\title{
Gingival Route of Administration
}

National Cancer Institute

\section{Source}

National Cancer Institute. Gingival Route of Administration. NCI Thesaurus. Code C149543.

Administration of a medicinal product to the gingivae. 